\title{
أثر الأنشطة الطلابية الدينية في قناعات طلبة الجامعات الفلسطينية
}

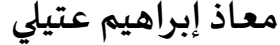 \\ طالب في مرحلة الدكتوراه - قسم الدعوة والقيادة - الجامعة الوطنية الماليزية - ماليزيا \\ muathateeli@gmail.com
}

\author{
محممد فيصل أشعري \\ محاضر في قسم الدعوة والقيادة في الجامعة الوطنية الماليزية - ماليزيا
}

faisal@ukm.edu.my

تُعد الأنشطة الدينية في الجامعات الفلسطينية من أبرز اتجاهات العمل الطلابي، حيث تهدف هذه الأنشطة إلى دعوة الطلبة للالتزام بتعاليم الإسلام الحنيف، والتحلي بأخلاقه الحسنة، والتخلي عن المنكرات والسلوكيات والعادات السيئة، وتستعمل

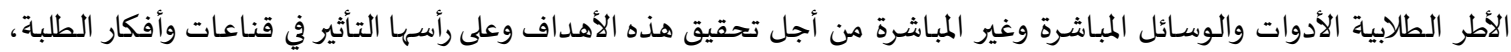
وتتنوع وسـائل وأدوات الأنشطة الدينية وكذلك تختلف في قدرتها على التأثير في قناعات الطلبة. تهدف هذه الدراسـة إلى اختبار مدى

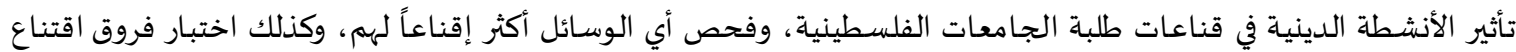
الطلبة بحسب الجنس والسنة الدراسية. واتبعت الدراسة المنهج الوصفي التحليلي، حيث رجع الباحث إلى الدراسـات السـابقة

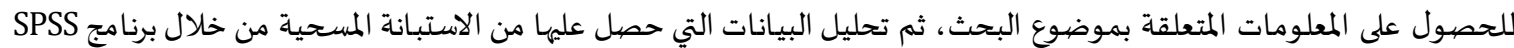

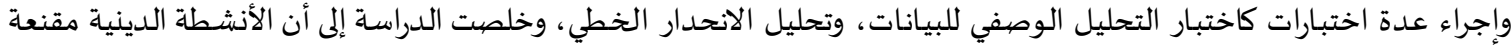

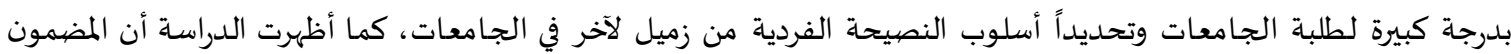
المقدم في تلك الأنشطة هو أكثر ما يقنع طلبة الجامعات، وأوضحت الدراسة أن طالبات الجامعات أكثر اقتناعاً بالأنشطة الدينية من

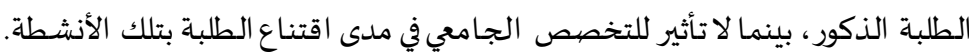

الكلمات المفتاحية: الأنشطة الدينية؛ الإقناع؛ الجامعات الفلسطينية.

\section{(c) (1)}

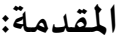

إنّ الدعوة إلى الله تعالى من أنبل الأعمال، التي يقوم بها العبد المسلم في حياته، كيف لا وهي وظيفة الأنبياء ومن سار على المان

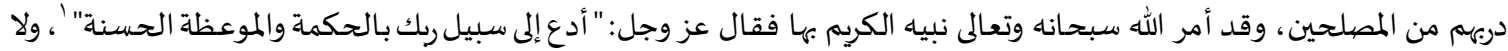
يقتصر عمل الإصلاح وتبليغ دين الله على فئة من المسلمين، فدعوة الناس إلى الخير والصلاح والأخلاق الكريمة ليست حكراً على أحدا،

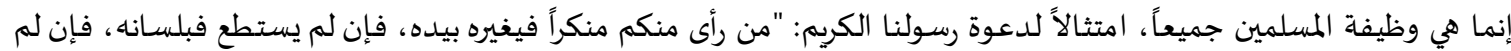

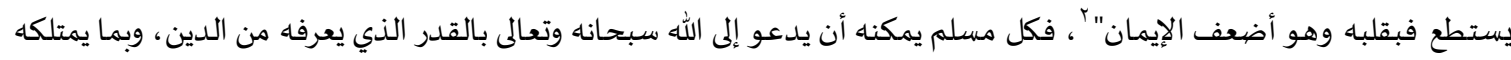

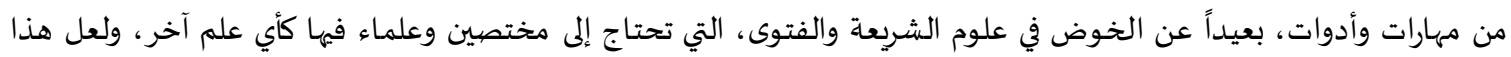
الطرح أقرب إلى معنى الدعوة بمفهوهها العام، وهنا يرى بعض أهل العلم أن الدعوة إلى الله: " نقل رسالة الإسلام من شخص لآئر الخر 
بهدف تفيير حال المدعو للأفضل" "، ويتسع هذا المفهوم للدعوة إلى الله تعالى من هم غير مسلمين أو من المسلمين أنفسهم كما هو

الحال في فلسطين، فالدعوة في المجتمع المسلم تختلف بأهدافها وأشكالها ومضيامينها عما عليه الحال في دعوة غير فير المسلمين.

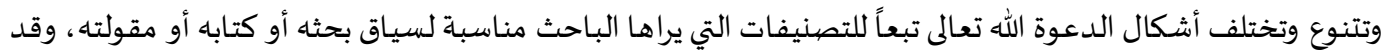
ورد في ذلك الكثير من التصنيفات والأشكال والأنواع، التي أسهب علماء علوم الدعوة ومفكروها في تأصيلها وشرحها، ولعل أكثر ما ركز

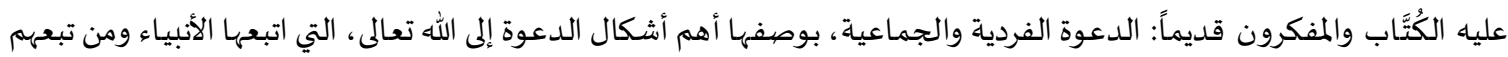
من الدعاة إلى الله .

إن ظهور الثورة التكنولوجية وتعدد أدوات الاتصال بين الناس، جعل مفهوم الدعوة وأشكاله يتطور ويتقدم تبعاً لتطور هذه الأدوات، وبدأت دراسة الدعوة بشكل إعلامي، وبدأت تظهر مفاهيم وعلوم جديدة في دراسة الدعوة وأدواتها كمفاهيم الاتصال

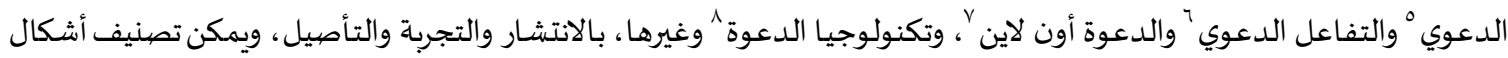

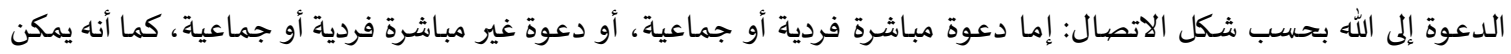
تصنيف الدعوة بحسب المستهدفين: إما دعوة غير المسلمين أو دعوة المسلمين كما هو الحال في المجتمع الفلسطيني.

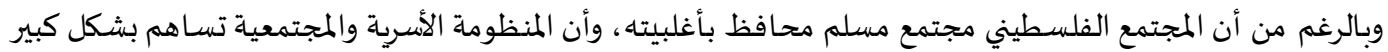
في تربية الشخصية المسلمة في فلسطين وبنائها، إلا أن تذكير الناس بدينهم ووعظهم، بما يزكي أنفسهم ويقربهم لربهم، ويبعدهم عن

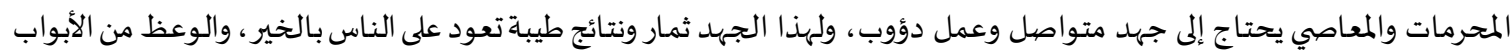
العظيمة في مقام الدعوة إلى الله تعالى، والخلق بحاجة ماسة إلياه، لكثرة انشغالهم بالدنيا وإعراضههم عن الآخرة وقسوة قلوبهم، وما

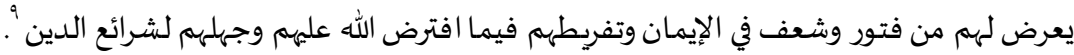
وتتنوع اتجاهات العمل الدعوي في فلسطين كالوعظ والإرشاد في المساجد والمناسبات، وكذلك دُور تحفيظ القران الكريم،

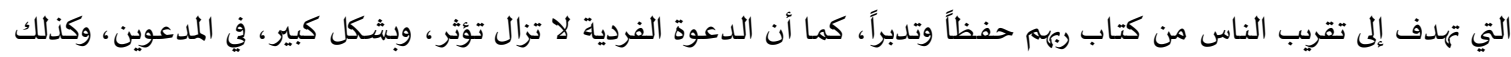
للإعلام الديني المحلي والعام دوراً مهماً في هذا المجال، وتعلب الأنشطة الدينية المتنوعة في المناسبات المختلفة دوراً المار بارزاً للتأثير في قناعات المدعوين وسلوكهم، وتأتي الأنشطة الدينية في الجامعات الفلسطينية على رأس هذه الأنشطة لما لها من تأثير في شريحة مهماة

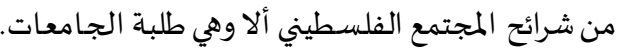

مشـكلة الدراسـة:

تتنوع الأنشطة الطلابية في الجامعات الفلسطينية وتختلف مضامينها، كالأنشطة النقابية والسياسية والخدمية وغيرها، وتحتل الأنشطة ذات المضامين الدينية المرتبة الثالثة في ترتيب الأنشطة من حيث العدد الكلي لتلك الأنشطة، حيث أظهرت دارسة

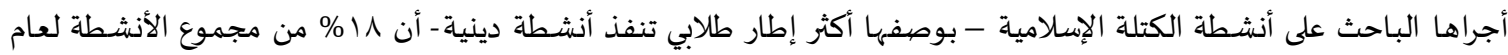

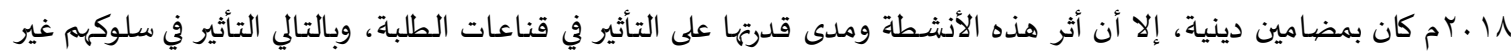
مقروء بلدراسـات مسحية تبين هذا الأثر ومداه، وتأتي هذه الدراسة لفحص وتقييم أثر الأنشطة الدينية على قناعات طلبة الجامعات إندات

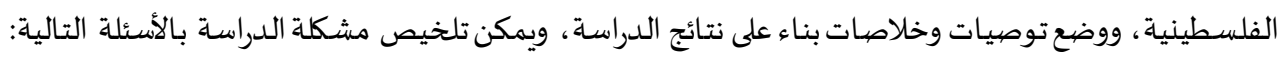
1. ما مدى تأثير الأنشطة الدينية في قناعات طلبة الجامعات الفلسطينية؟

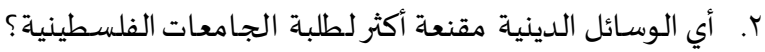

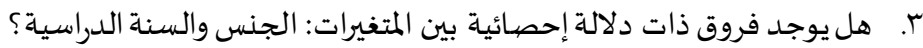

3 Rozina Abd Ghani \& Muhamad Faisal Ashaari, 2010, The Model of Online al-Dacwah al-Fardiyyah, Proceeding 3rd International Conference on 2010, 13-20

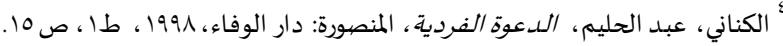

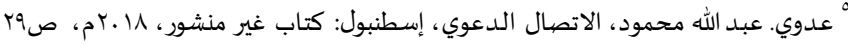

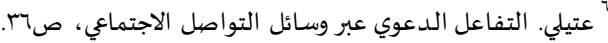

7 Rozina Abd Ghani \& Muhamad Faisal Ashaari, 2010, The Model of Online al-Dacwah al-Fardiyyah, Proceeding 3rd International Conference on 2010, 13-20.

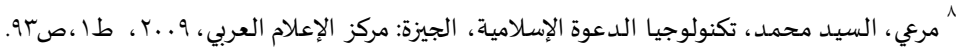
" البلهيد. خالد سعود، فقه الدعوة، مقالة منشورة على موقع صيد الفوائد، WwW.Saaid.net. 
أهداف الدراسـة: أهد

تهدف هذه الدراسة لتحقيق ثلاثة أهداف رئيسية ، هي: 1. اختبار مدى تأثير الأنشطة الدينياة في قناعات طلبة الجامعات الفلسطينية.

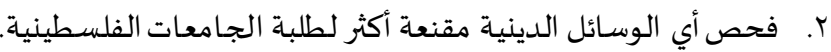
r. فحص الفروق الشخصية بين المتغيرات: الجنس والسنة الدراسية.

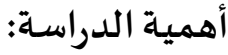

تكمن أهمية هذه الدراسة في أمرين، أولهما: يتعلق بموضيوعها، وهو قياس أثر الأنشطة الدينية، التي تقيمها الأطر الطلابية

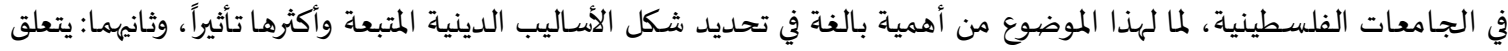

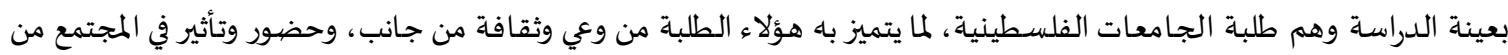
جانب آخر.

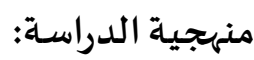

اتبعت الدراسـة المنهج الوصفي التحليلي، حيث رجع الباحث للدراسـات السـابقة للحصول على المعلومات المتعلقة بموضوع البحث، ثم تحليل البيانات التي حصل علهها من الاستبانة المسحية من خلال برنامج SPSS، وإجراء عدة اختبارات كاختبار التحليل

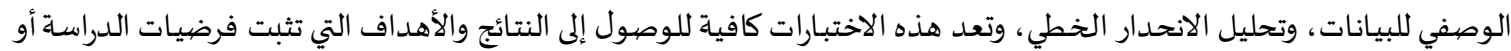

تنفيها.

الدراسـات السـابقة:

استعان الباحث بالعديد من الدراسـات السابقة ذات الصلة ههذه الدراسة، في مجالات الحركة الطلابية الفلسطينية وأنشطتها في الجامعات الفلسطينية، ومن هذه الدراسات التي رجع إلها الباحث: الطهراوي. كمال حسن عطية، المهارات القيادية لدى أعضياء المجالس الطلابية وعلاقتها بمستوى الأنشطة الطلابية في الجامعات الفلسطينية، غزة: أكاديمية الإدارة والسياسة للدراسات العليا، رسالة مقدمة لنيل درجة الماجستير، 10 ـأم. وخلصت الدراسة إلى مجموعة من التوصيات أبرزها: ضرورة رعاية الطلبة الذين تتوافر لديهم المهارات القيادية وإبراز قدراتهم،

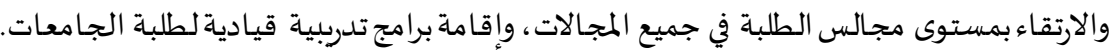
الطهراوي. جميل، أبو كرش. يوسف، دور الأنشطة اللامنهجية في إشباع الحاجات النفسية لدى طلبة الجامعة الإسلامية في

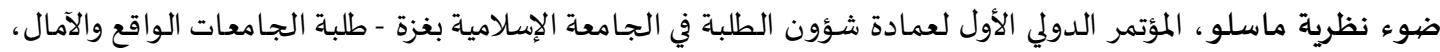

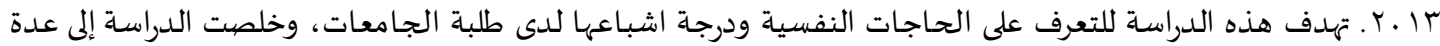

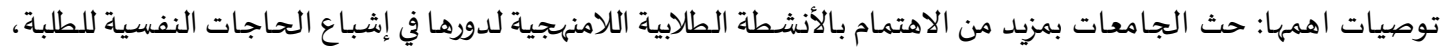
وضرروه تعيين مرشدين نفسيين في عمادات شؤون الطلبة لتكوين فرق عمل جادة مع الاخصائيين الاجتماعيين والمشرفين الرياضيين لتحسين جودة الخدمات المقدمة.

هالعز. فؤاد علي، عساف. محمود عبد المجيد، دور الأنشطة الطلابية في تنمية الوعي الوطني القائم على الانتماء لدى طلبة الجامعات الفلسطينية بمحافظة غزة، غزة: المؤتمر الدولي الأول لعمادة شؤون الطلبة في الجامعة الإسلامية بغزة طلبة

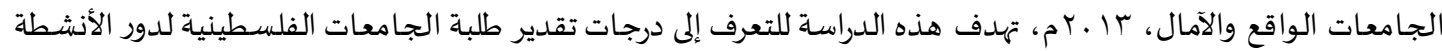
الطلابية في تنمية الوعي الوطني القائم على الانتماء لديهه، وخلصت الدراسة إلى عدة توصيات، أبرزها: التأكيد على أن الهدف

الأسـاسي للوعي الوطني لدى طلبة الجامعات هو تكوين المواطن الصالح القادر على المشاركة الايجابية في تنمية مجتمعاه. كلاب. أمجاد رضوان محمد، تصهور مقترح لتطوير دور الأنشطة الطلابية في الجامعات الفلسطينية لتعزيز الوحدة الوطنية

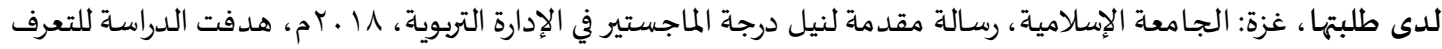

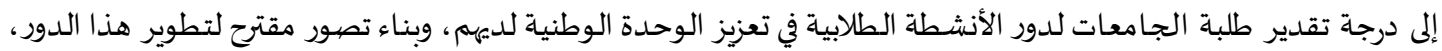


وخلصت الدراسة لعدة توصيات أهمها: توظيف التصور المقترح من الباحثة، والأخذ بأهدافه وأنشطته في ترسيخ دور الأنشطة

$$
\text { الطلابية التي تعزز الوحدة الوطنية. }
$$

\section{الإطار النظري للدراسـة: الأنشطة الدينية في الجامعات الفلسطينية}

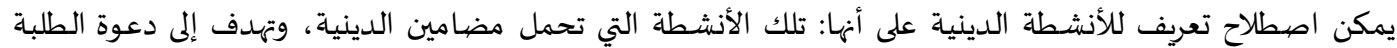
للالتزام بتعاليم الإنلام الحنيف، والتحلي بأخلاقه الحسنة، والتخلي عن المنكرات والسلوكيات والعادات السيئة ، كدعوة الطلبة إلى الى الئل

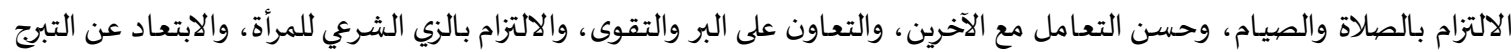
والسفور والاختلاط وغير ذلك من الأحكام والآداب الإسلامية.

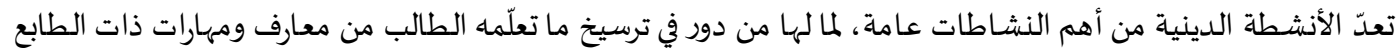

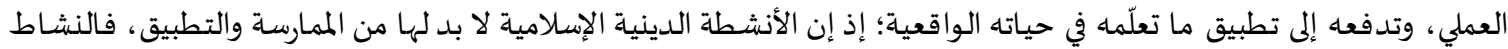

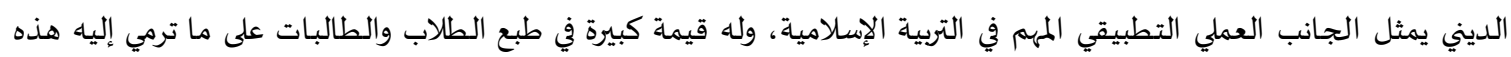

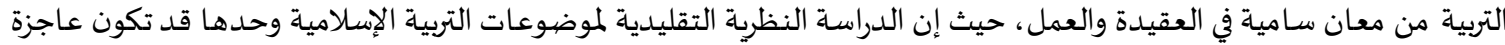

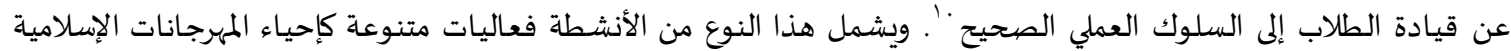

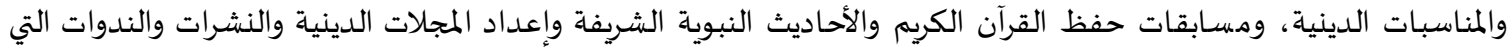
تتناول القضايا الإسلامية المختلفة ".

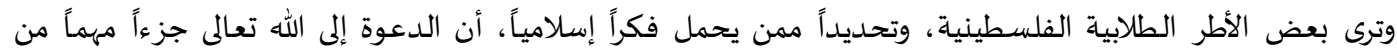

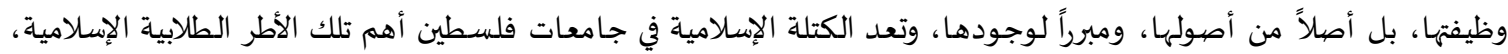

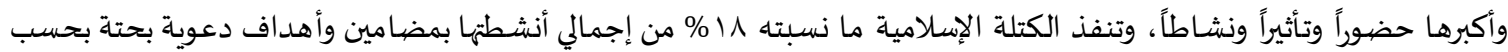

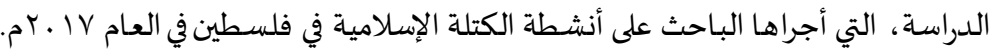

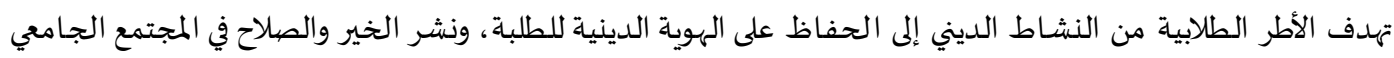
بشكل خاص، والمجتمع الفلسطيني بشكل عام، يشكل حلقة مهمة في منظومة العمل الدعوي في فلسطين، لاعتبارئ العار الهات أهمها:

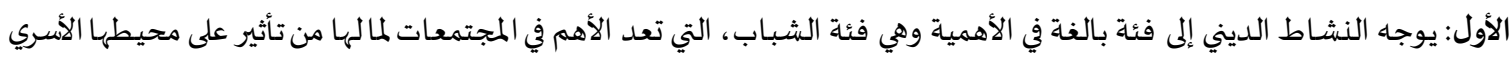
والمجتمعي. الثاني: تُعدُّ الجامعات ميداناً كبيراً ومهماً، للتنظير والتأثير في الآخرين لما توفره البيئة الجامعية من أدوات وظروف لا تتوفر في أماكن أخرى. الثالث: تسعى التيارات الفكرية والأيدولوجية في الجامعات إلى استقطاب الشباب لها كاليسارين والعلمانيين، مما جعل من وجود

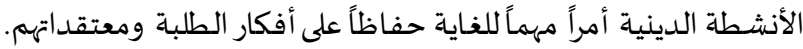

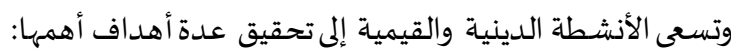
ا ا. الالتزام بالدين الإسلامي والقيم الإيجابية

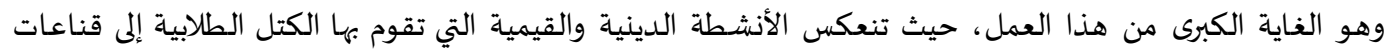

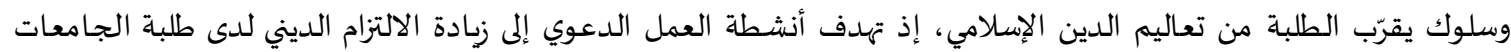

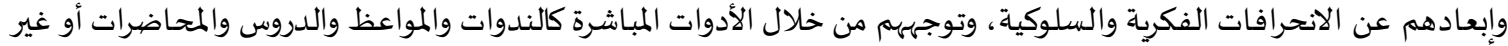

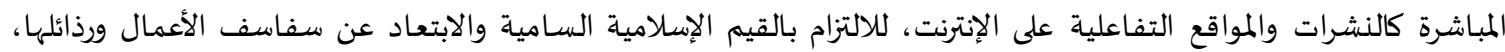
وتنشط في سبيل ذلك المصليات ومنتديات القرآن الكريم وكليات الشربعة والكثير من الوسائل والأدوات الدينية على مدار الإنات العام.

'أبو شريخ. شاهر ذيب، تقويم ممارسة طلبة المرحلة الثانوية والأساسية للأنشطة الدينية اللاصفية في المدارس الأردنية، مصر: مجلة التربية جامعة الأزهر،

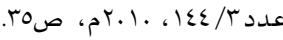

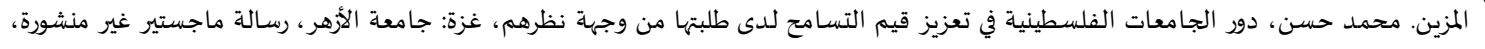


r. التوعية الدينية والقيمية

وتهدف الأنشطة الدينية والقيمية إلى نشر الوعي الديني بين طلبة الجامعات، من خلال العديد من الأنشطة التوعوية والفكرية التي تركز على مفاهيم الفكر الإسلامي، وعلوم الفقه الإسلامي، والسنة النبوية الشريفة، والحديث النبوي، والأخلاق

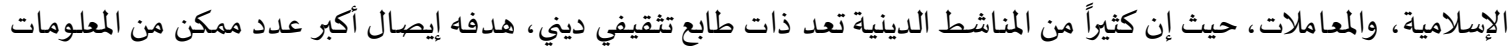

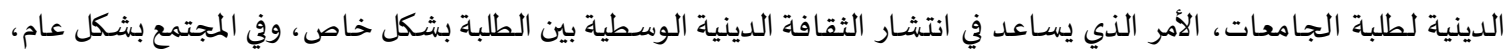
وتسهم الندوات والمحاضرات، والنشرات والمجلات المطبوعة في ذلك، إضافة إلى المضيامين الدينية والقيمياة، التي تنتشر على وسائل

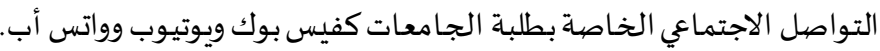
r. الحفاظ على الهوية الدينية

من الأهداف المهمة للعمل الدعوي في الجامعات، هو الحفاظ على الهوية الإسلامية للمجتمع ، فالحضور المستمر للأنشطة

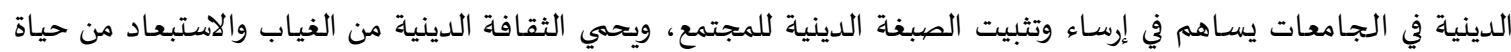

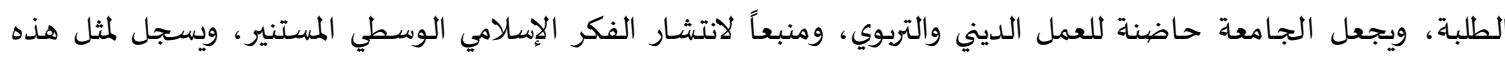

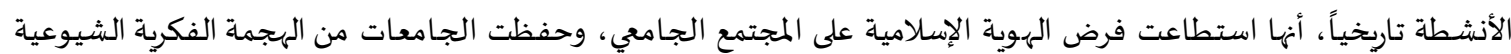
والعلمانية التي استهدفته منذبداية مشوار الحركة الطلابية وما زالت تمارس هذا الاستهداف حتى يومنا هذا.

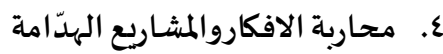
تُعد الأنشطة الدينية في الجامعات، حصناً من أهم الحصيون، التي تتصديدى لمحاولات تشويه العقيدة والفكر الإسلامي لدى

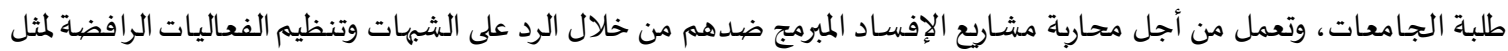
تلك المحاولات، ويتعرض طلبة الجامعات بشكل مستمر إلى صنوف كثيرة من محاولات التأثير في أفكارهم، وإبعادهم عن دينهم

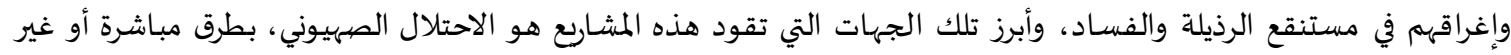
مباشرة، كما أن هناك العديد من الأيدولويجيات، والتوجهات الفكرية التي تسعى لانفتاح المجتمع تحت شعارات الحرية والية والمسـاواة والتحضر وغيرها من المصطلحات الرنانة، تهدف في نهاية المطاف إلى خلق بيئة طلابية بعيدة عن منهج الدين الإسلامي.

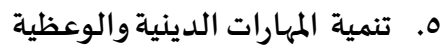

تساعد الأنشطة الدينية على تنمية مهارات الدعوة والوعظ لدى طلبة الجامعات، وتساهم في تأهيل شـاب جامعي قادر على الماتل حمل أمانة الدين والدعوة إليه، ويتيح انخراط الطلبة في تلك الأنشطة اكتسابهم تجارب وقدرات في إدارة المشارع الدينية، وكيفية

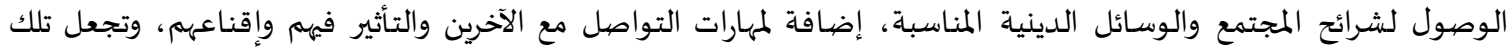
الأنشطة من الطالب الجامعي بغض النظر عن تخصصيه داعية للدين والأخلاق الفاضلة، وتشعر الطلبة بالمسؤولية تجاه دينهم وهويتهم الإسلامياة، وقد تخرج من الجامعات العديد من الدعاة والوعاظ المبدعين والمتميزين والذين كان لهم أثر وبصيمة في المجتمع على الصعيد الدعوي، وهناك فرق ملحوظ بين من يدرس العمل الشرعي ولا يمارس العمل الدعوي في الجامعات، وبهات وبين من ينتشر في أروقتها يدعو طلبتها للالتزام بدينهم والتحلي بأخلاق إسلامهم. ويمكننا تعريف العمل الدعوي الطلابي في الجامعات الفلسطينية على أنه: "مجموعة من الأنشطة الطلابية ذات

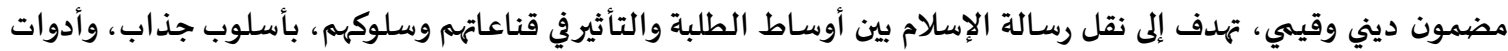

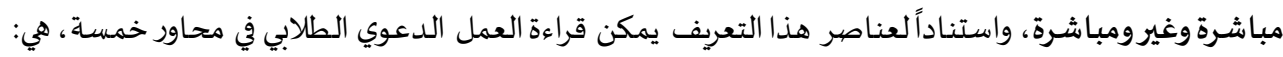

المحور الأول: المضمون الديني للأنشطة

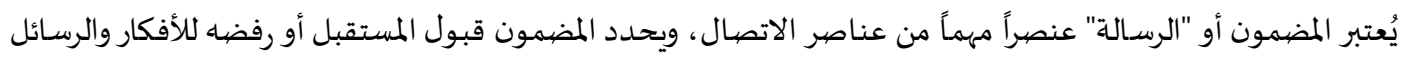

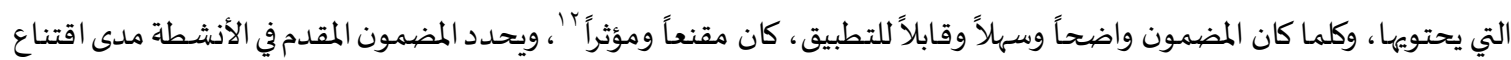

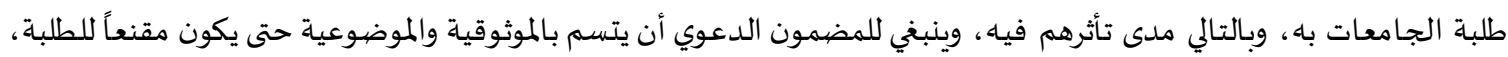

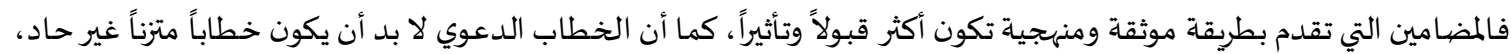

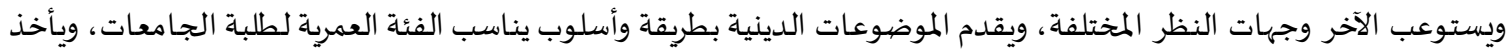

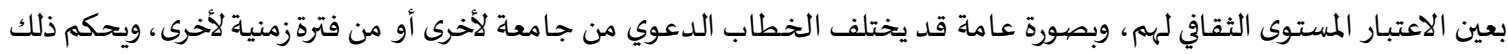

T المؤسسة العامة للتدريب التقني والمهني، مهارات التعامل مع الغير، السعودية: الإدارة العامة لتصميم وتطوير المنتهج، وبعا هـ، (د.ط)، ص10. 
في أغلب الأحيان الظروف المحيطة بالواقع الطلابي والمجتمعي بشكل عام، كما أن لطبيعة الأشخاص القائمين على الأنشطة الدينية تأثير في صياغة طبيعة الخطاب.

المحور الثاني: التأثيرفي أفكاروقناعات الطلبة

تثبت الدراسـات أن تفاعل البشر فيما بينهم يؤدي بالضرورة إلى تبادل الأفكار والأفعال، وأن هذا التفاعل عبارة عن مؤثرات واستجابات تؤدي إلى التغيير في الأفكار والمعتقدات، تبدأ بالتعرف والتقييم والضبط ثم اتخاذ القرارات والتوتر وانتهاءً بالتكامل

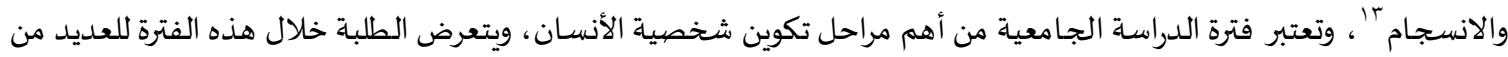

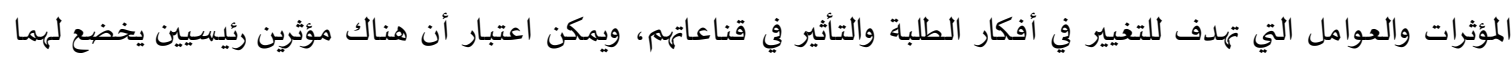

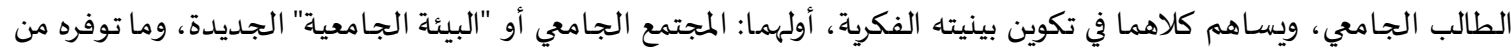

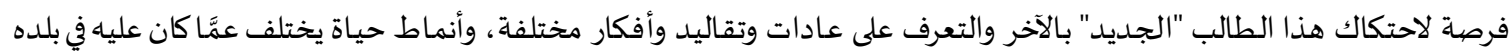

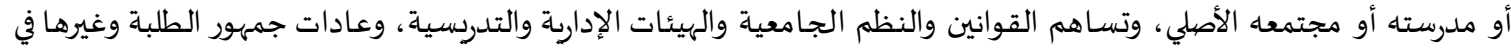

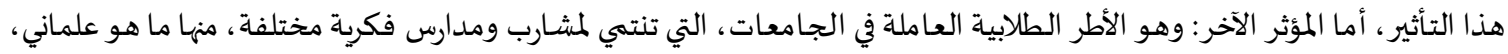

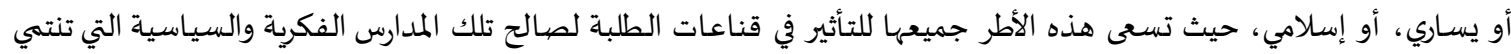

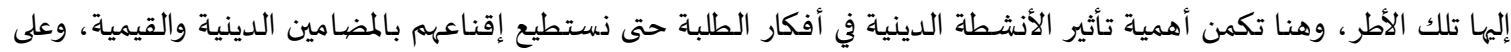

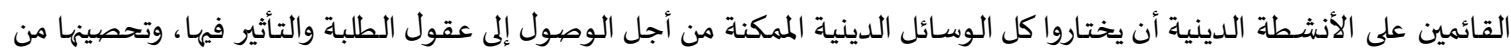
أي أفكار ومعتقدات هدامة ، وغرس القيم والأفكار الحميدة في عقولهم ونفوسهم.

المحور الثالث: التأثيرفي سلوك الطلبة إن عملية التأثير في أفكار الآخرين وإقناعهم سواء بتغيير أو تعزيز مفاهيم وقناعات موجودة عندهم سيؤثر في سلوكهم

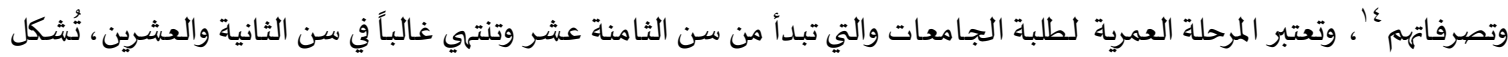
أهم المحطات التي تُحدث تغييراً في شخصية هؤلاء الطلبة، وتُسههم بشكلٍ كبيرٍ في صقل شخدية شخصية الطالب وتغيير ملامحها الفكرية

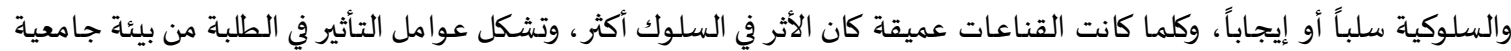

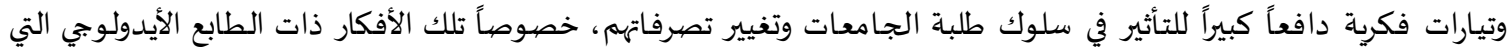
تحدث انعطافاً كبيراً في سلوك الطالب، في معظم الأحيان، وجنباً إلى جنب مع التأثير التلقائي البيئي في سلوك الطلبة ، تسعى الأطر الطلابية للتأثير الفكري على طلبة الجامعات ومحاولة تجنيدهم فكرياً وتنظيمياً، ويقع الطالب في أتون معركة فكرية، لا لا يجد مناصاً

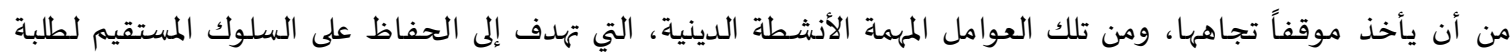

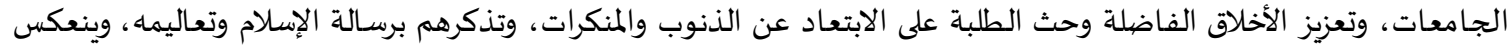

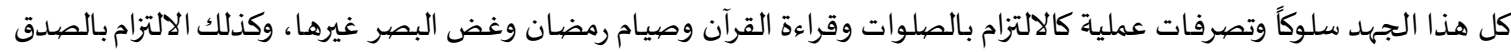
والأمانة ومحاسن الاخلاق، إلى غير ذلك من سلوكيات يدعو لها الإسلام الحنيف.

المحور الر ابع:جاذبية الأنشطة الدينية أصبح من المُسلَّمات أن هناك ارتباطاً كبيراً بين التأثير في قناعات الناس وسلوكهه، وبين جاذبية الأشخاص الوسائل

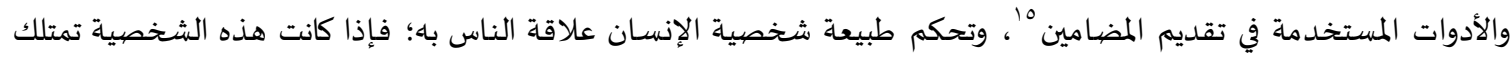

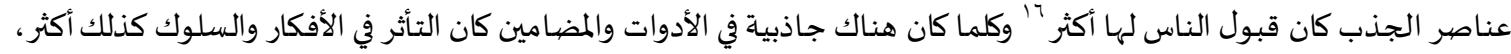
ويُقصد في الجاذبية هنا ما تمتلكه الأنشطة الدينية من عوامل تجعل من الطلبة أكثر إقبالاً عليها وتأثراً بها، سواء أكان ذلك الك الكان متعلقاً

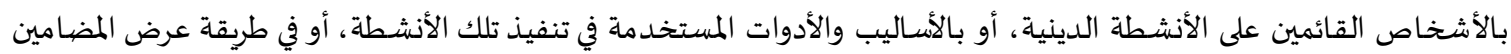

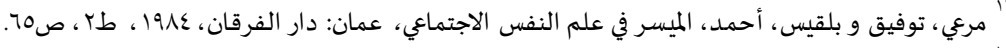

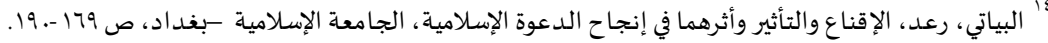

15 N.W. Jankowski, 2001, Interaction And Interpersonal Behavior In Computer-Mediated Academic Forums, The Public, 97-102.

16 Katelyn Y. A. McKenna \& John A Bargh, 2000, Plan 9 From Cyberspace: The Implications of the Internet for Personality and Social Psychology, Personality and Social Psychology Review, 57-75. 


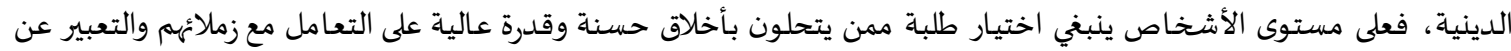

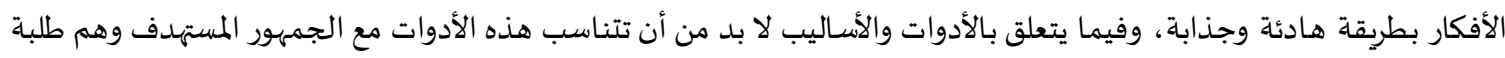

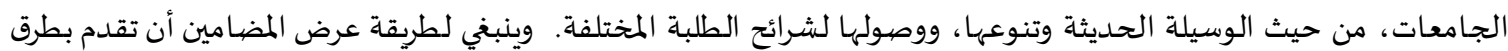
متنوعة تناسب الأفكار المقدمة، واختيار أفضل شكل في تقديمها من أجل تحقيق هدف يجذب الطنات الطلبة لهذه المضامين.

المحور الخامس: الوسائل المباشرة وغير المباشرة

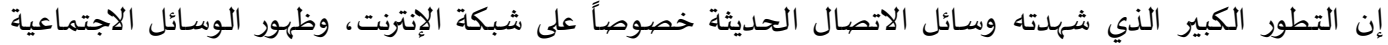

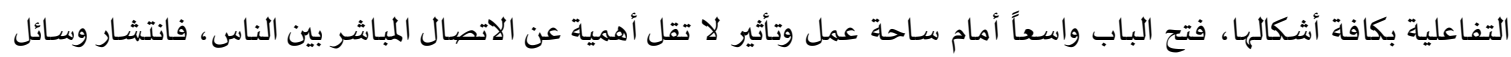

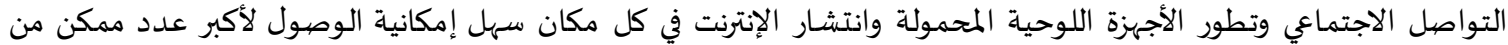

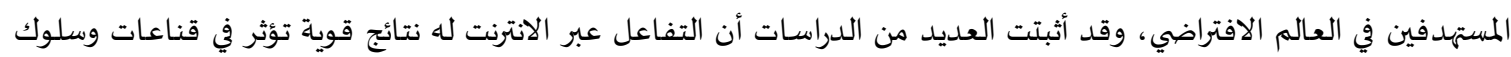

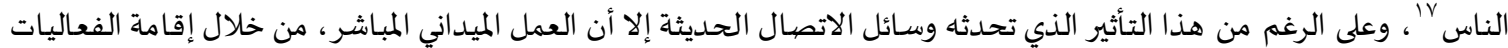

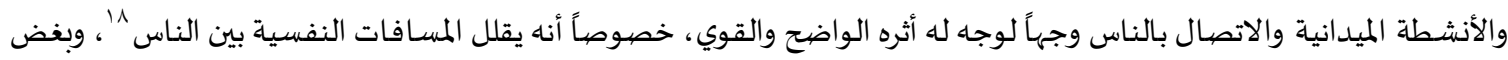

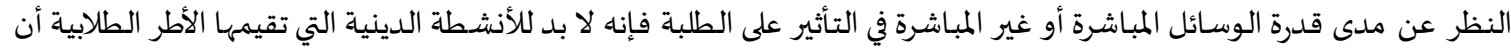

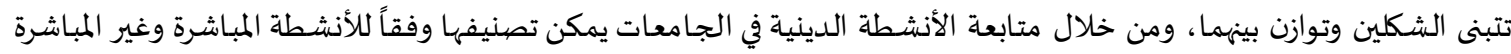
كما يأتي:

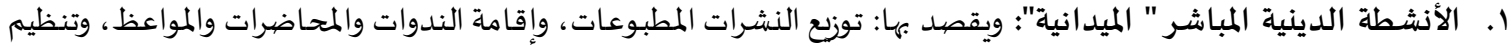

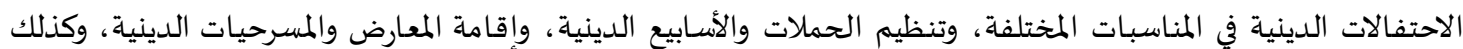

دعوة فردية من زميل في الجامعة. r. الأنشطة الدينية غير المباشرة "عبر الإنترنت": وهي استعمال وسائل التواصل الاجتماعي المختلفة (فيس بوك، واتس أب، يوتيوب،

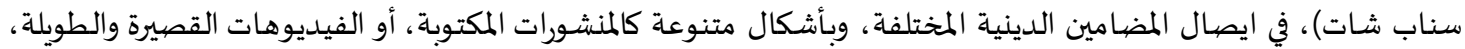
والتصاميم التي تعبر عن أفكار دينية.

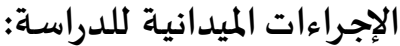 مجتمع الدراسة وعينته}

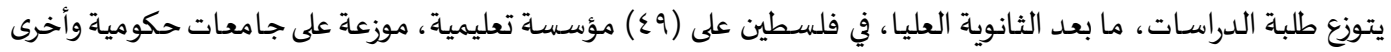

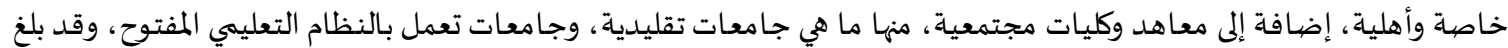

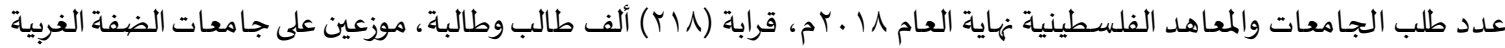

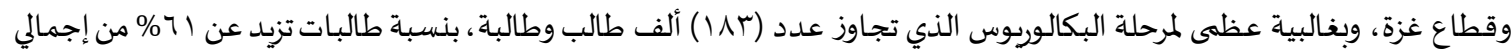

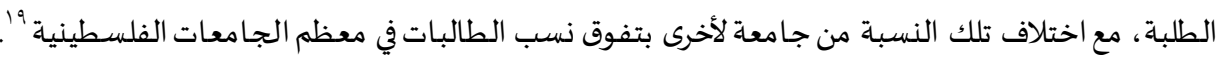

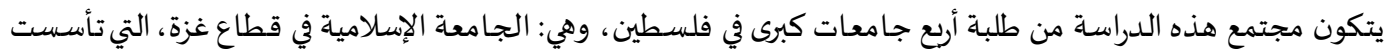

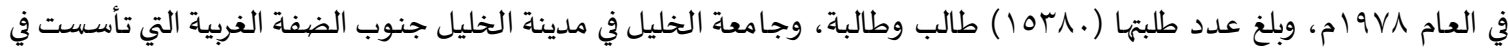

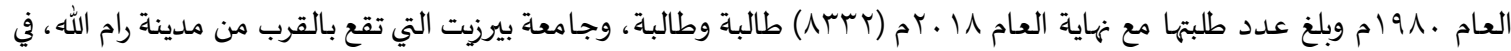

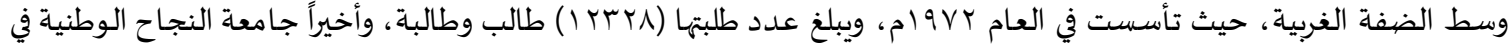

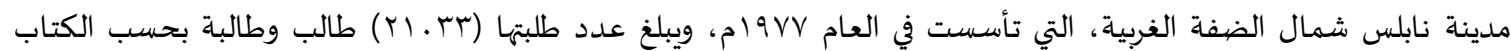

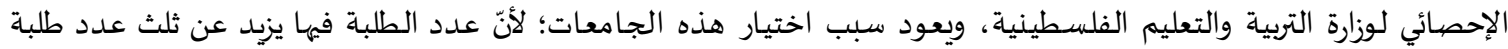

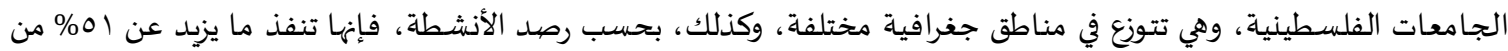
إجمالي الأنشطة الدينية في الجامعات الفلسطينية.

18 Swan, Karen. 2002, Building Learning Communities in Online Courses: the importance of interaction, Education, Communication \& Information, 2(1), 24-49. 19 الكتاب الإحصائي السنوي الصادر عن ورزاة التربية والتعليم العالي الفلسطيني، رام الله: فلسطين، لا ـبم. 
تكونت عينة هذه الدراسة من طلبة مرحلة البكالوربوس في الجامعات الأربع "الجامعة الإسلامية، جامعة الخليل، جامعة

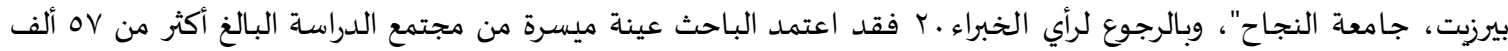

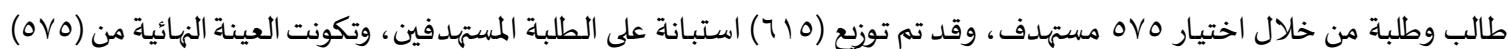

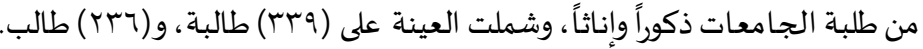

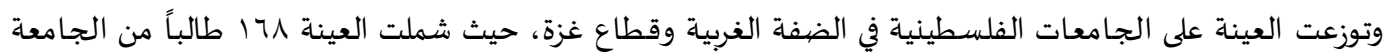

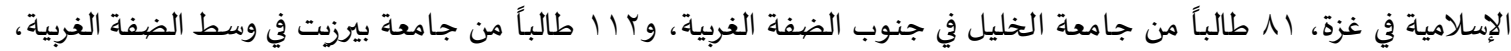

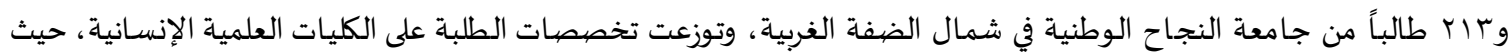

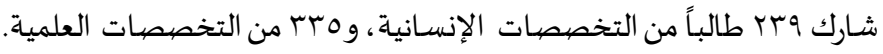
أدوات الدراسة

تم تصميم استبانة كأداة لجمع البيانات، حيث أجاب عليها المستهدفون، وقسمت الاستبانة إلى قسمين أساسيين، الأول: يشمل البيانات الشخصية؛ كالجنس والجامعة والتخصص، والثاني: يأتي لاستكشاف أثر الأنشطة الدينية في إقناع طلبة الجامعات،

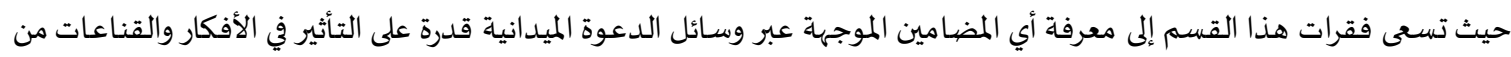
المحاضرات والمنشورات والمعارض والمسرحيات، وكذلك الدعوة الفردية من زميل جامعي، كما يسعى المحور لمعرفة قدرة المضامين الدينية الإلكترونية على التأثير في أفكار وقناعات الطلبة من فيديوهات قصيرة وضيرة ومنشورات وتصاميهم دينية. صبدق الأداة

قام الباحث بالتحقق من صدق الأداة، حيث تم التأكد من صددق الاستبانة بطريقتين، هما:

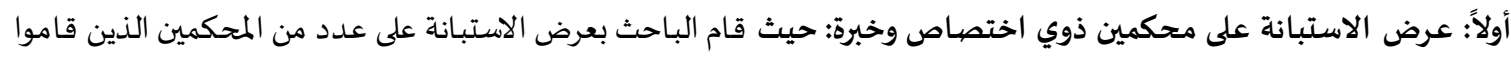

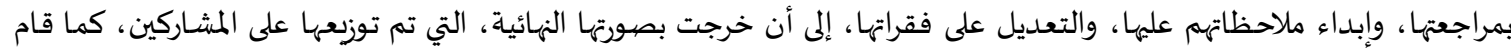

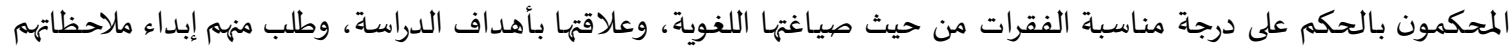

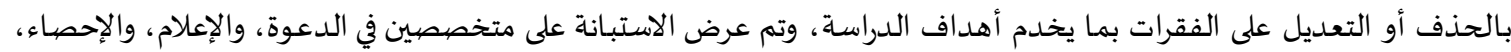
والتربية، وهذا يدلل على صدق هذه الأداة وقوتها.

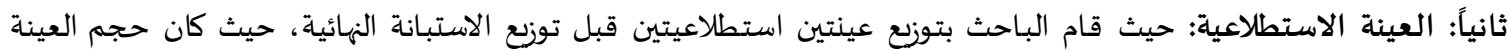
الاستطلاعية الأولى ـ r استبانة لاختبار صدقها. وقد عمد الباحث إلى اختيار هذه العينة كونها جزء من مجتمع الدراسة الذي ستوزع

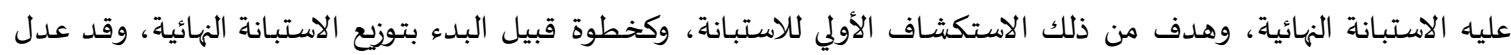
الباحث بعض الفقرات بناء على هذه النتائج بحذف بعض الفقرات التي تبين وجود تكرار أو صعوبة في فهمها، كما وزع الباحث عينة

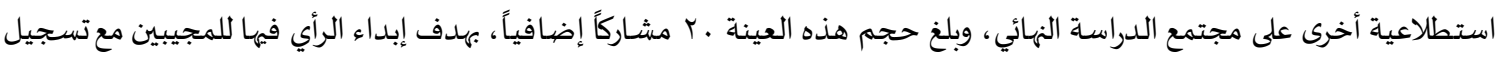

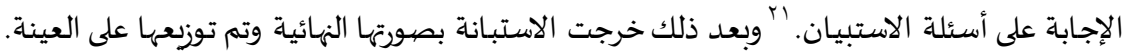

ثبات الاستبانة

يُقصيد بثبات الاستبانة الاستقرار في نتائجها وعدم تغييرها بشكل كبير فيما لو تم إعادة توزعها على أفراد العينة عدة

مرات، حيث يستخدم معامل ألفا كرونباخ Cronbach's Alpha Coefficient لقياس ثبات الاستبانة. وفي هذه الدراسة تم التحقق من ثبات الأداة باستخدام معامل ثبات كرونباخ ألفا، فطبقت الأداة على (.oV.

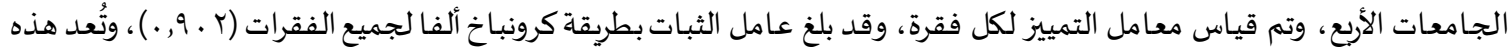

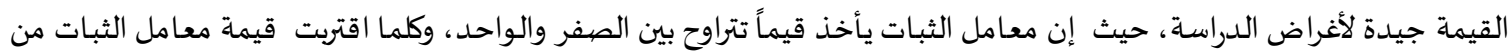

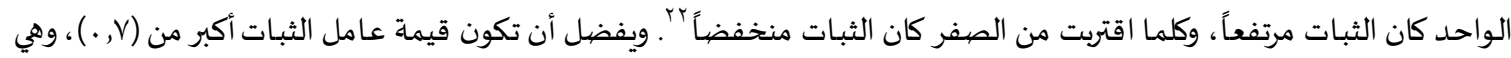
في هذه الدراسـة مرتفعة وتعبر عن ثبات الاستبانة.

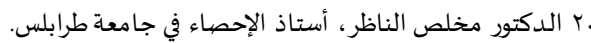

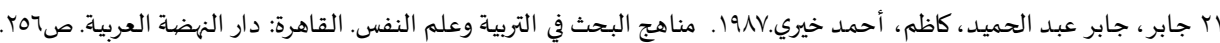

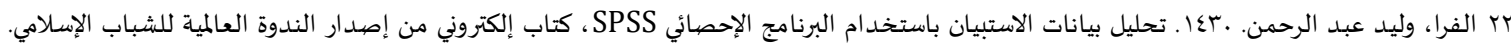




$$
\text { صددق المقياس والاتساق الداخلي }
$$

لمعرفة مدى اتسـاق كل فقرة من فقرات الاستبانة مع مجالها والعامل الذي تنتهي إليه هذه الفقرة، قام الباحث باختبار

الاتسـاق الداخلي للفقرات، بحساب معاملات الارتباط بين كل فقرة من فقرات المجال بالنسبة لدرجة المجال الكلية.

جدول( ) ( ) معامل الارتباط بين كل فقرة

\begin{tabular}{|c|c|c|c|}
\hline القيمة الاحتمالية & معامل الارتباط بيرسون & الفقرة & 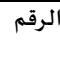 \\
\hline.,$\ldots 1$ & ${ }^{* *} \cdot, \wedge .7$ & الندوات والمحاضرات الطلابية الدينية مقنعة لي & 1 \\
\hline.,$\ldots 1$ & ${ }^{* *} ., \mathrm{V} 01$ & أقتنع بالمضمون الديني المقدم في العروض المسرحية الدينية الطلابية & r \\
\hline$\ldots, \ldots$ & ${ }^{* *} ., \mathrm{VA \Lambda}$ & أقتنع بمضمون المنشورات الدينية الطلابية & r \\
\hline.,$\ldots 1$ & **.,, 07 & أقتنع بمضمون الحفلات الدينية الطلابية & $\varepsilon$ \\
\hline.,$\ldots 1$ & ${ }^{* *} .$, V ro & أقتنع بأهمية المعارض الدينية الطابية & 。 \\
\hline.,$\ldots 1$ & ${ }^{* *} \cdot, 794$ & أقتنع عندما ينصحني زميلي في الجامعة بنصيحة دينية & 7 \\
\hline$\ldots, \ldots$ & ${ }^{* *} ., \mathrm{v} \vee \mathrm{q}$ & أقتنع بمضمون الفيديوهات الدينية الطلابية القصيرة التي تنشر في وسائل التواصل الاجتماعي & $\mathrm{v}$ \\
\hline.,$\ldots 1$ & ${ }^{* *} \cdot, \lambda \cdot \Lambda$ & أقتنع بمضمون المنشورات الدينية الطلابية المنشورة في وسائل التواصل الاجتماعي & $\wedge$ \\
\hline$\ldots, \ldots$ & ${ }^{* *} ., \mathrm{V}$ V & أقتنع بمحتوى التصاميم الدينية الطلابية المنشورة في وسائل التواصل الاجتماعي & 9 \\
\hline
\end{tabular}

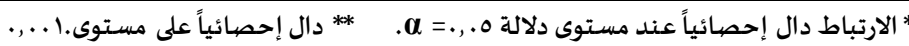

يتضح من الجدول السابق أن هناك اتساقاً داخلياً بين الفقرات، أثبتته نتيجة اختبار معامل الارتباط بين الفقرات والمحور، وجميعها دالة إحصائياً على مستوى اجل . ., .

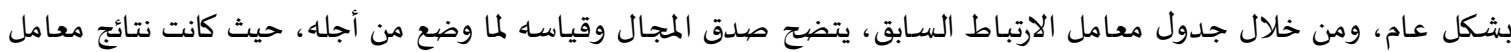

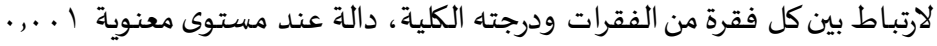

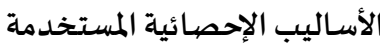

استخدم الباحث برنامج SPSS للتحليل، معتمداً الأسـاليب الإحصيائية الآتية:

ا . التحليل الوصفي: ويتضمن المتوسط الحسابي، الذي يعبر عن متوسط إجابات العينة على سؤال محدد، والانحرافات المعيارية

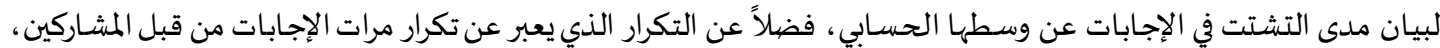
والنسب المئويةة ، التي تعبر عن عدد التكرار نسبة لعدد المستجيبين للأداة. r. ت تحليل الانحدار الخطي المتعدد لاختبار تأثير المتغيرات المستقلة في المتغير التابع بهدف التنبؤ.

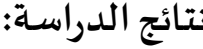

1. ما مدى تأثير الأنشطة الدينية في قناعات طلبة الجامعات الفلسطينية ؟

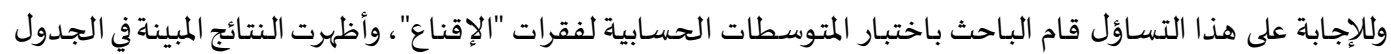
رقم (r) أن عبارات محور إقناع النشاط الدعوي قد حصلت على متوسط حسابي بين درجات عالية ومتوسطة من وجهاة نظر أفراد

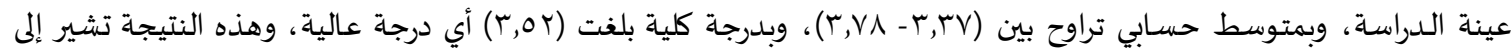

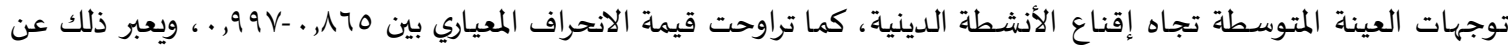
تشتت ضئيل في إجابات أفراد عينة الدراسـة. جدول(Y) : نتائج فقرات الإقناع

\begin{tabular}{|c|c|c|c|c|}
\hline الدرجة & الاتحراف المعياري & المتوسط الحسابي & الفقرة & الرقم \\
\hline عالية &., $99 \mathrm{~V}$ & $r, \varepsilon_{0}$ & الندوات والمحاضرات الطالابية الدينية مقنعة لي & 1 \\
\hline عالية &., 909 & $r, \varepsilon \varepsilon$ & أقتنع بالمضمون الديني المقدم في العروض المسرحية الدينية الطالبية & r \\
\hline عالية & $\cdot, 170$ & $r, \varepsilon V$ & أقتنع بمضمون المنشورات الدينية الطابية & r \\
\hline متوسطة &., $9 \mathrm{rq}$ & $r, r v$ & أقتنع بمضمون الحفلات الدينية الطلابية & $\varepsilon$ \\
\hline عالية &., 907 & $r, 07$ & أقتنع بأهمية المعارض الدينية الطلابية & ० \\
\hline عالية &., $9 \leqslant 7$ & $r, \mathrm{r} \Lambda$ & أقتنع عندما ينصحني زميلي في الجامعة بنصيحة دينية & 7 \\
\hline عالية & ., $99 \varepsilon$ & $r, 77$ & ألاجتمنع به ضمون الفيديوهات الديذ ية الطلاجية الق صيرة التي تذ شر في وسائل التوا صل & $\mathrm{v}$ \\
\hline
\end{tabular}




\begin{tabular}{|c|c|c|c|c|}
\hline عالية & . 9 , qrr & $r, \varepsilon \wedge$ & أقتنع بمضمون المنشورات الدينية الطلابية المنشورة في وسائل التواصل الاجتماعي & $\wedge$ \\
\hline عالية &., $9 \times 7$ & $r, 0 r$ & أقتنع بمحتوى التصاميم الدينية الطلابية المنشورة في وسائل التواصل الاجتماعي & 9 \\
\hline عالية & & r,or & الدرجة الكلية لإقناع النشاط الدعوي & \\
\hline
\end{tabular}

r. أي الوسائل الدينية مقنعة أكثر لطلبة الجامعات الفلسطينية؟

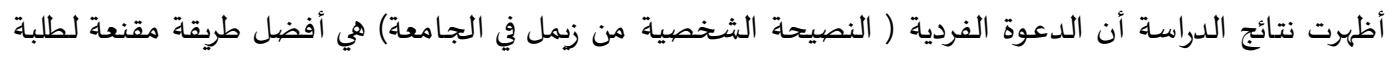

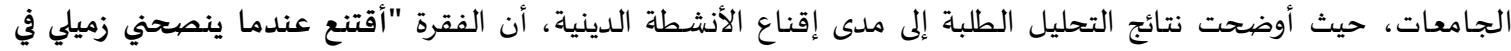

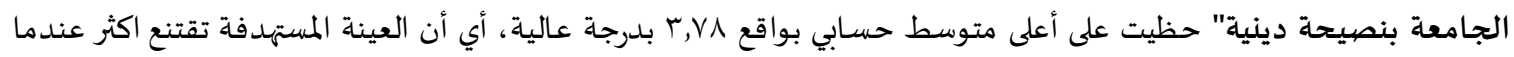
تستقبل النصيحة من زميل في الجامعة،، وكما حصلت الفقرة "أقتنع بمضمون الحفلات الدينية الطلابية"، على أقل متوسط

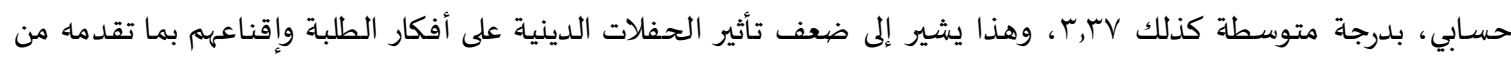

مضيامين دينية.

كما وتعتقد عينة الدراسة أن المحتوى المقدم في ندوات والمحاضرات والمنشورات والتصاميم والفيديوهات، وكذلك المعارض والمسرحيات مقنعة بدرجة عالية، باستثناء وسيلة واحدة ترى عينة الدراسـة أنها ليست مقنعة بدرجة عالية وهي "الحفلات الدينية" التي تقام في الجامعات.

r. هل يوجد فروق ذات دلالة إحصيائية بين المتغيرات: الجنس والسنة الدراسية؟ الدمات

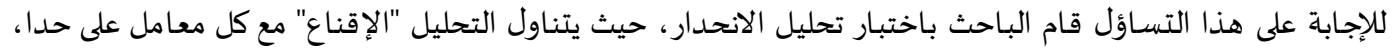
حيث سيتم دراسة تأثير المتغيرات المستقلة ( الأنشطة الدينية الميدانية، والأنشطة الدينية الإلكترونية، والمضيامين الدينية) ومتغيرات الشخصية (الجنس، والجامعة، والتخصص) على والإقناع في الأنشطة الدينية الطلابية. وقد قام الباحث بعمل اختبار التعدد الخطي للمتغيرات المستقلة، وتبين عدم وجود ارتباط عال بين العوامل، وعدئ وعدم وجود التعدد الخطي بين المتغيرات المستقلة، باختبار معامل تضخم التبايّن (VIF) واختبار التباين المسموح (Tolerance) لكل متغيّر من

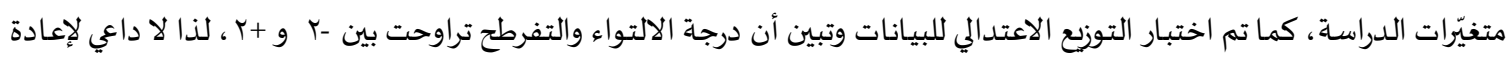
هذه الاختبارات.

ولدراسة تأثير العوامل المستقلة والشخصية على الإقناع في الأنشطة الدينية الطلابية، كشفت نتيجة تحليل الانحدار

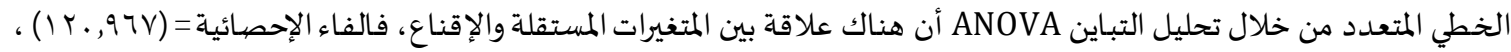

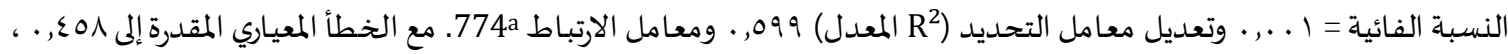

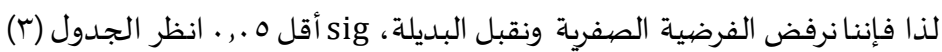

جدول(ץ): تحليل التباين ANOVA

\begin{tabular}{|c|c|c|c|c|c|}
\hline النسبة الفائية & الفاء الإحصبائية & متوسط المربعات & درجة الحرية & مجموع المربعات & النموذج \\
\hline \multirow[t]{3}{*}{,$+ \ldots 1$} & $1 T \cdot, 97 \mathrm{~V}$ & To, 209 & $\mathrm{~V}$ & $|V \lambda, r| r$ & الخطي \\
\hline & & .,Y. & 077 & $119,1 r \mid$ & الخطأ المعياري \\
\hline & & & OVTr & $r q V, r r \varepsilon$ & المجموع \\
\hline
\end{tabular}

ويتبين من جدول رقم (ع) Model Summery أن نسبة الارتباط بين العوامل والإقناع، هي (774a.)، وبتربيع هذه القيمة

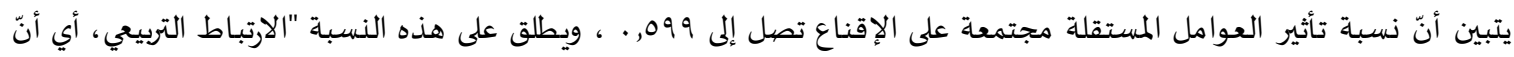

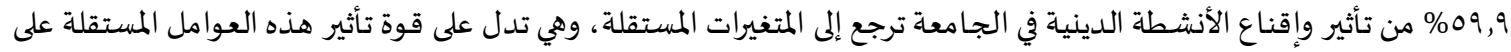
الإقناع، فضلاً عن تأثيرات عوامل أخرى على الجاذبية. ويتبين أيضاً، أن نسبة الارتباط التربيعي المعدل هي ع 09, •وهي أقل من الارتباط التربيعي بنسبة بسيطة. وعموماً فإن هذه النتيجة تدل

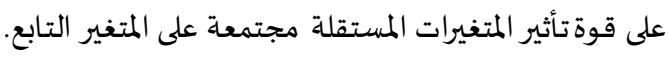




\begin{tabular}{|c|c|c|c|}
\hline الارتباط التربيعي المعدل & الارتباط التربيعي & RالارتباطR & النموذج \\
\hline., $09 \leq$ &., 099 & ${ }^{a} \cdot, V V \varepsilon$ & 1 \\
\hline
\end{tabular}

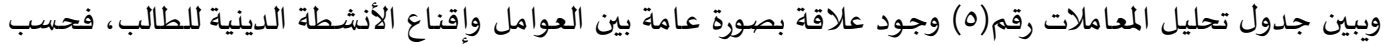

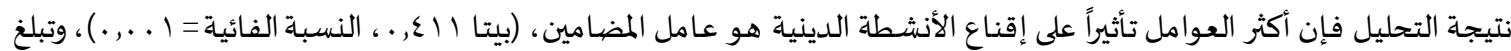

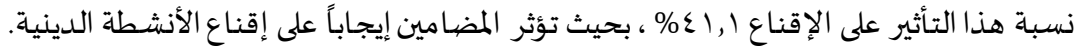

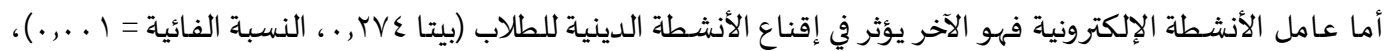

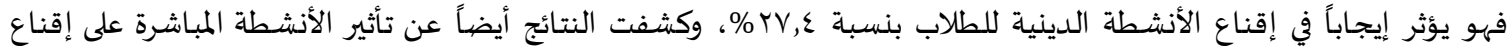

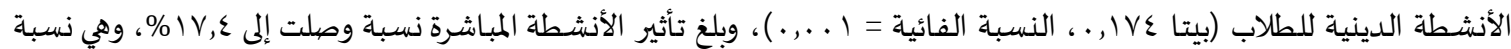
تعبر عن التأثير الإيجابي للأنشطة المباشرة.

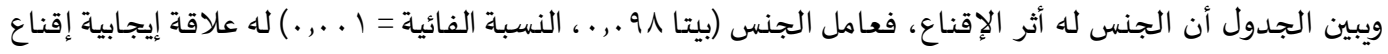
الأنشطة الدينية للطلاب بنسبة ^, 9\%، وتفسيره أن الإناث أكثر اقتناعا من الذكور بالأنشطة الطلابية بهذه النسبة.

جدول(o):المعاملات Standardized

\begin{tabular}{|c|c|c|c|c|c|}
\hline \multirow[t]{2}{*}{$\begin{array}{c}\text { النسبة الفائية } \\
\text { sig }\end{array}$} & \multirow[t]{2}{*}{$\begin{array}{l}\text { تي } \\
\mathrm{T}\end{array}$} & \multirow{2}{*}{$\begin{array}{c}\text { معاملات مقننة } \\
\text { Standardized Coefficients } \\
\text { Beta بيتا }\end{array}$} & \multicolumn{2}{|c|}{$\begin{array}{c}\text { Unstandardized معاملات غيرمقننة } \\
\text { Coefficients }\end{array}$} & \multirow[t]{2}{*}{ النموذج } \\
\hline & & & $\begin{array}{l}\text { Std. الخطأ المعياري } \\
\text { Error } \\
\end{array}$ & B بي B & \\
\hline$\ldots$ & $0, \ldots 1$ & - & . 1179 & , $79 \varepsilon$ & المحكك \\
\hline ., & r, 00r. &., .91 & .,. & ., & الجنس \\
\hline$\ldots r$ & $r, 901-$ & $\cdot, .41-$ &., .17 &.,.,$\varepsilon \gamma-$ & الجامعة \\
\hline ., VAV & ., YVY & $\ldots, \ldots-$ &.,.$\varepsilon$. &., $.11-$ & التخصص \\
\hline$\cdot, \ldots$ & $\varepsilon, 0 . \varepsilon$ &., $1 \vee \varepsilon$ & . ro &., $10 \mathrm{~V}$ & الأنشطة المباشرة \\
\hline$\cdot, \ldots$ & $V, T V 7$ & . $T V \varepsilon$ & . Tr & .,YVI & الأنشطة الإلكترونية \\
\hline$\cdot, \ldots$ & $11, \varepsilon 00$ &., . 11 & r &., rVA & المضمون \\
\hline
\end{tabular}

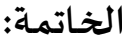

تسهم الأنشطة الدينية التي تقيمها الأطر الطلابية في الجامعات الفلسطينية بالتأثير في أفكار الطلبة وتغيير قناعاتهم بدرجة تراوحت بين عالية ومتوسطة لمحور الإقناع، وبالتالي تغير سلوكهم نحو الأفضل، سواء كانت هذه الأنشطة ميدانية أو حتى الأنى

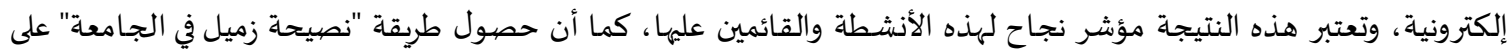

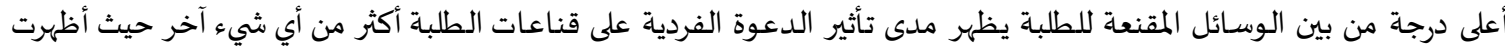

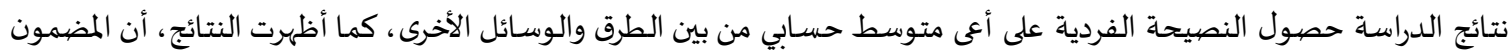

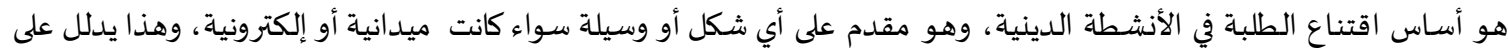

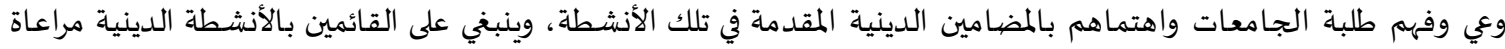

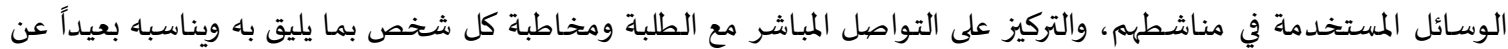

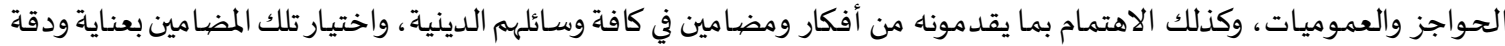

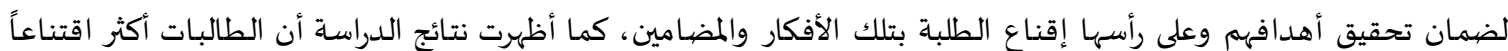
بالأنشطة الطلابية من الطلاب الذكور، بينما لا يوجد فروق بين الطلاب والطالبات بحسب الكليات الكات الدراسية. 


$$
\begin{aligned}
& \text { المراجع: }
\end{aligned}
$$

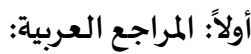

$$
\begin{aligned}
& \text { ا. البليهد، خالد سعود، فقه الدعوة، مقالة منشورة على موقع صيد الفوائد، www.saaid.net. }
\end{aligned}
$$

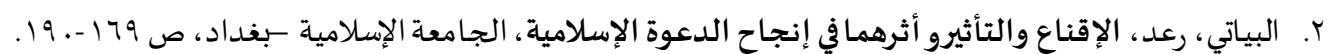

$$
\begin{aligned}
& \text { r. جابر، جابر عبد الحميد، كاظم، أحمد خيري، (19/VV) مناهج البحث في التربية وعلم النفس. القاهرة: دار النهضية العربية. }
\end{aligned}
$$

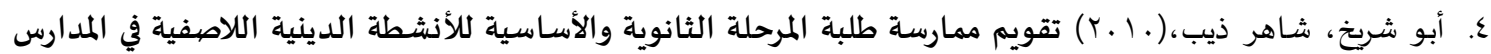

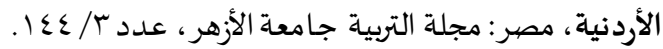

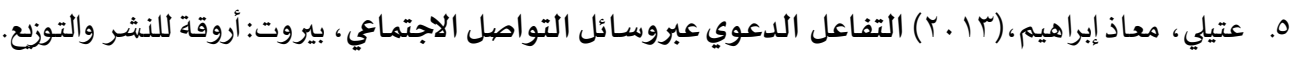

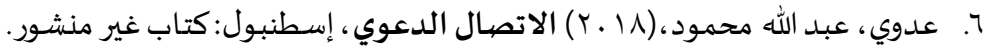

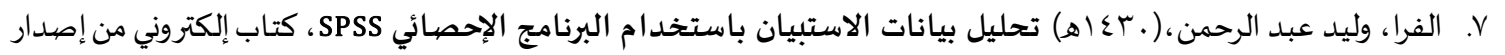

$$
\begin{aligned}
& \text { الندوة العالمية للشباب الإسلامي. }
\end{aligned}
$$

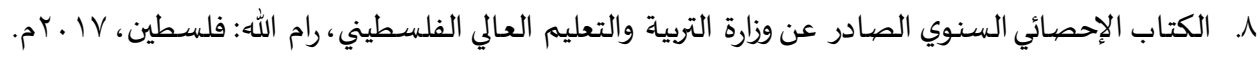

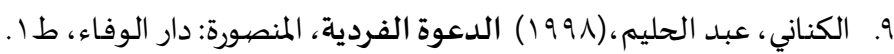

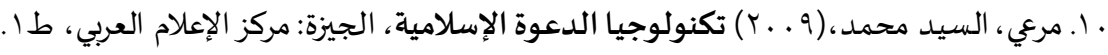

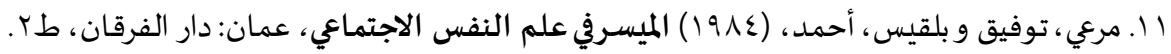

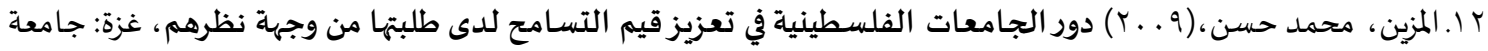

$$
\begin{aligned}
& \text { الأزهر، رسالة ماجستير غير منشورة. } \\
& \text { با. المؤسسة العامة للتدريب التقني والمهني، (وץ ع اهـ) مهارات التعامل مع الغير ، السعودية: الإدارة العامة لتصميم وتطوير المنتهج، } \\
& \text { (د.د) }
\end{aligned}
$$

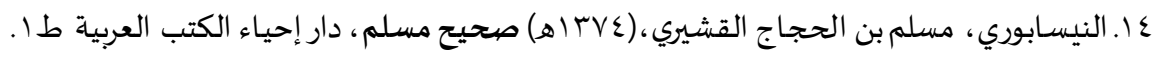$$
\text { ثانياً: المراجع الأجنبية: }
$$

[1] Katelyn Y. A. McKenna \& John A Bargh, Plan 9 From Cyberspace: The Implications of the Internet for Personality and Social Psychology, Personality and Social Psychology Review, 4(1) (2000), 57-75, https://doi.org/10.1207/s15327957pspr0401_6

[2] N.W. Jankowski, Interaction And Interpersonal Behavior In Computer-Mediated Academic Forums, The Public, (2001)

[3] Rozina. Abd Ghani \& Muhamad. Faisal Ashaari, The Model of Online al-Dacwah al-Fardiyyah, Proceeding 3rd International Conference on 2010.

[4] Swan, Karen. Building Learning Communities in Online Courses: the importance of interaction, Education, Communication \& Information, 2(1)(2002), 23-49, https://doi.org/10.1080/1463631022000005016 
(p) Refaad

رفاد للدراسـات والأبحاث

www.refaad.com

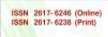

المجلة الدولية للدراسات الإسلامية المتخصصصية

e-ISSN 2617-6246 , p-ISSN 2617-6238

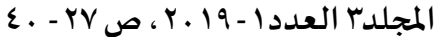

https://doi.org/DOI:10.31559/sis2019.3.1.2

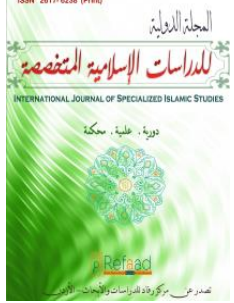

\title{
The Impact of Student Religious Activities on The Convictions of Palestinian University Students
}

\author{
Muath Ibrahim Ateeli \\ PhD student in Department of Dakwah and Leadership Studies, Faculty of Islamic Studies, National \\ University of Malaysia, Malaysia \\ muathateeli@gmail.com \\ Muhamad Faisal Asha'ari \\ Lecturer in Department of Dakwah and Leadership Studies, Faculty of Islamic Studies, National \\ University of Malaysia, Malaysia \\ faisal@ukm.edu.my
}

Abstract. Religious activities across Palestinian universities are considered as the most important student work aspects. The purpose of these activities is to urges students to adhere the regulations of Islam, to show good morals, and to leave the immoral and bad deeds.The students parties are usually use direct and indirect tools in order to achieve these goals. And on the top of these goals is the Influencing of students 'convictions and ideas. There are variety of religious activities tools and its ability to influence students' convictions. The study aims to test the impact of religious activities on the convictions of Palestinian university students, and examine any means more convincing to them, as well as to test the differences of student conviction by sex and school year. The study adopts the analytical descriptive method. Meanwhile, many prior studies was reviewed and analysed to obtain precious information related to the study. Then, questionnaire survey was designed and distributed to obtain the data, which was analyzed using SPSS approach. The data was tested by conducting descriptive analysis and linear regression analysis. The study concluded that, religious activities are convincing the universities students, specifically the method of individual advice from one colleague to another. The study also showed that the content presented in these activities is the most convincing for the students. The study also showed that female university students are more convinced of religious activities than male students, while university specialization does not affect the extent of students' conviction of these activities.

Keywords: Religious Activities; Conviction; Palestinian University.

\section{References:}

[1] 'dwy. 'bd Ạllh Mḥmwd, Ạlạtṣạl Ạld'wy, A̧sțnbwl: Ktạb Ghyr Mnshwwr, (2018)

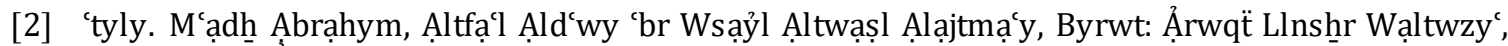
(2013)

[3] Ạlblyhd. Khạld Scwd, Fqh Ạld'wh, Mqạlh Mnshwwrh 'la Mwq' Ṣyd Ạlfwậ̉d, www.saaid.net.

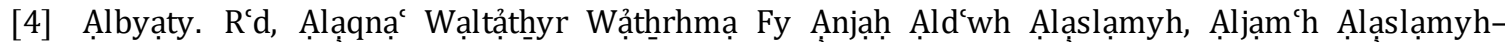
Bghạad, pp.169-190. 
[5] Ạlfrạ. Wlyd 'bd Ạlrḥmn, Tḥlyl Byạnạt Ạlạstbyạn Bạstkḥdạm Ạlbrnạmj Ạlạhṣạ̉y Spss, Ktạb Ảlktrwny Mn A̦Șdạr Ạlndwh Ạl'ạlmyh Llshbạb Ạlạslạmy, (1430h)

[6] Jạbr. Jạbr 'bd Ạlḥ̣myd \& Kạzm, Ạ̉ḥmd Khnyry, Mnạhj Ạlbḥthِ Fy Ạltrbyë W'lm Ạlnfs. Ạlqạhrh: Dạr Ạlnhụh Ạl'rbyh, (1987)

[7] Katelyn Y. A. McKenna \& John A Bargh, Plan 9 From Cyberspace: The Implications of the Internet for Personality and Social Psychology, Personality and Social Psychology Review, 4(1) (2000), 57-75, https://doi.org/10.1207/s15327957pspr0401_6

[8] Ạlknạny. 'bd Ạlḥlym, Ạld'wh Ạlfrdyh, Ạlmnșwrh: Dạr Ạlwfạ’, Ṭ1, (1998)

[9] Ạlktạb Ạlạhṣạyy Ạlsnwy Ạlṣạdr 'n Wzạrẗ Ạltrbyë Wạlt'lym Ạl'ạly Ạlflsțny, Rạm Ạllh: Flsțnn, (2017).

[10] Mrcy. Ạlsyd Mḥmd, Tknwlwjyạ Ạld'wh Ạlạslạmyh, Ạljyzh: Mrkz Ạlạiclạm Ạll'rby, Ṭ1, (2009)

[11] Mrcy. Twfyq \& Blqys. Ạ̉ḥmd, Ạlmysr Fy 'Im Ạlnfs Ạlạjtmậy, 'mạn: Dạr Ạlfrqạn, Ṭ2, (1984)

[12] Ạlmw̉ssh Ạl'ạmh Lltdryb Ạltqny Wạlmhny, Mhạrạt Ạlt’ạml M Ạlghyr, Ạlscwdyh: Ạlạjậrh Ạl'ạmh Ltșmym Wtțwyr Ạlmnthj, (D.Ṭ), (1429h)

[13] Ạlmzyn. Mḥmd Ḥsn, Dwr Ạljạm‘ạt Ạlflsțynyh Fy T'zyz Qym Ạltsạmḥ Lda Ṭlbthạ Mn Wjḧ̈ Nẓrhm, Ghza: Jạmđ̈̈ Alạ̉zhr, Rsạlẗ Mạjstyr Ghyr Mnshwwrh, (2009)

[14] Ạlnysạbwry. Mslm Bn Ạlḥ̣jạj Ạlqshyry, Șhỵ̣ Mslm, Dạr A̧̧hyạ’ Ạlktb Ạl'rbyh, Ṭ1, (1374h)

[15] N.W. Jankowski, Interaction And Interpersonal Behavior In Computer-Mediated Academic Forums, The Public, (2001)

[16] Rozina. Abd Ghani \& Muhamad. Faisal Ashaari, The Model of Online al-Dacwah al-Fardiyyah, Proceeding 3rd International Conference on 2010.

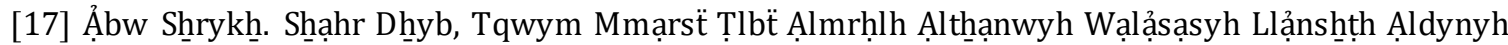
Ạllạṣfyh Fy Ạlmdạrs Ạlạ̉rdnyh, Mṣr: Mjlh Ạltrbyh Jạm đ̣̈ Ạlạ̉zhr, 'dd 3/ 144(2010)

[18] Swan, Karen. Building Learning Communities in Online Courses: the importance of interaction,

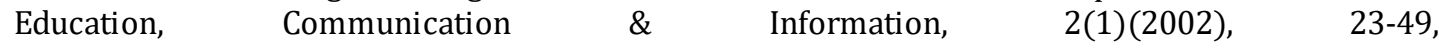
https://doi.org/10.1080/1463631022000005016 